\title{
Shiga Toxin-Producing Escherichia Coli Isolated From Lettuce Samples in Tehran, Iran
}

\author{
Somayeh Mazaheri ${ }^{1, *} ;$ Siavosh Salmanzadeh Ahrabi ${ }^{1}$; Mohammad Mahdi Aslani ${ }^{2}$ \\ ${ }^{1}$ Department of Biology, Alzahra University, Tehran, IR Iran \\ ${ }^{2}$ Department of Microbiology, Pasteur Institute of Iran, Tehran, IR Iran \\ *Corresponding author: Somayeh Mazaheri, Department of Biology, Alzahra University, Tehran, IR Iran. Tel: +91-98012807, E-mail: somayemazaheri@yahoo.com
}

Received: May 20, 2013; Revised: August 5, 2013; Accepted: December 21, 2013

\begin{abstract}
Background: During the last decade, the prevalence of foodborne diseases due to contaminated food as well as the outbreaks of diseases due to Shiga toxin-producing Escherichia coli (STEC) strains has increased.

Objectives: The aim of this study was to evaluate the prevalence and antibiotic resistance pattern of STEC strains in lettuce samples. Since lettuce is used as a raw vegetable in salads, the rates of infections caused by this vegetable are high.

Materials and Methods: A total of 100 samples collected from Tehran, Iran, were transported to the laboratory, homogenized by a stomacher in E. coli broth containing cefixime, and cultured on MacConkey agar medium. Their DNA was extracted by boiling method and polymerase chain reaction (PCR) was performed, using five primers targeting the $s t x 1, s t x 2$, fliCh7, rbfO157, and eaeA genes. Susceptibility testing against ampicillin, imipenem, cephalosporin, tetracycline, aminoglycosides, chloramphenicol and quinolones was performed using disk diffusion method.

Results: Eight samples were positive for presence of STEC strains, three contained stx1, five contained stx2, and one sample was positive for presence of both rbf0157 and fliCh7. They were susceptible to all the antibiotics except for ampicillin and tetracycline.

Conclusions: This study indicated the contamination of lettuce by STEC strains and its possible role as the source of infection. Resistance to both tetracycline and ampicillin may be considered as an emergency alarm for a multidrug resistance of STEC strains.
\end{abstract}

Keywords:Shiga toxigenic Escherichia coli; Iran

\section{Background}

During the past decade, the patterns of diseases generated by Shiga toxin-producing Escherichia coli (STEC) strains have changed from a clinical novelty to a global public health problem. This group of E. coli strains can cause a spectrum of human diseases, ranging from symptom-free carriage to severe bloody diarrhea and even life-threatening disorders, such as hemolytic-uremic syndrome (HUS) and hemorrhagic colitis (HC) (1-4). The infections caused by the STEC strains have been reported from over 30 countries where E. coli O157:H7strain has been the most common serogroup. Furthermore, the prevalence of foodborne diseases due to consumption of contaminated foods and/or water has increased worldwide $(5,6)$.

Among the contaminated foods, fresh fruits and vegetables have been increasingly recognized as a source of foodborne outbreaks in many regions of the world (6-8). Although, the outbreaks of the diseases attributable to STEC strains have been associated with consumption of raw vegetables; the epidemiological investigations implicated lettuce as the most likely source of the outbreak (9-11). As examples, large STEC-related outbreaks due to consumption of lettuce were observed in Sweden and Spain, where association was found between outbreaks caused by E. coli 0157:H7 strain and the consumption of lettuce $(10,11)$.

Among the reservoirs of these pathogenic E. coli strains, cattle may be considered as a principal source, because the studies on the prevalence of $\mathrm{E}$. coli $\mathrm{O} 157: \mathrm{H} 7$ in cattle feces have shown a wide variety of positive cases in different countries (12-14). The way by which these groups of pathogens can spread over the farm lands may be the ubiquitous employment of bovine manure in the agriculture (15). Fresh vegetables can be contaminated by these strains through bovine manure, irrigation with contaminated or waste water, and further contact with infected animals and/or humans $(16,17)$. We have previously shown the importance of STEC in diarrheal diseases of both Iranian children and adults (18).

\section{Objectives}

The main purpose of this study was to detect the presence of STEC in lettuce samples collected from Tehran, Iran and to evaluate the antibiotic resistance patterns of the isolates. The extensive use of lettuce as a raw vegetable in homemade meals and restaurants served as a prime motivator for inspection of the prevalence and the genotype distribution of STEC in the lettuce samples. 
Mazaheri S et al.

\section{Materials and Methods}

\subsection{Sample Collection and Bacterial Culture}

One hundred lettuce samples were collected weekly from various farm lands in Tehran between June and September 2011. Every sample was packed in a separate stomacher bag (Interscience, France) and transported (in ice) to the laboratory, where they were immediately processed by a stomacher instrument (Bag Mixer400 VW, Interscience, France). Enrichment and processing of the samples were carried out according to previously described protocols (7). Briefly, $25 \mathrm{~g}$ of each sample was homogenized by the stomacher in its bag containing 225 $\mathrm{mL}$ E. coli broth (EC) medium (Merck, Germany), supplemented with $0.05 \mathrm{mg} / \mathrm{L}$ cefixime (Daana Pharmaceutical co., Iran). This antibiotic enhances the enrichment of STEC strains.

After overnight incubation at $37^{\circ} \mathrm{C}$, a portion of the mixture was spread over a MacConkey agar plate (Merck, Germany) and was further incubated at $37^{\circ} \mathrm{C}$ overnight. A sweep from the semi-confluent area of the plate was used for DNA extraction for polymerase chain reaction (PCR) detection of STEC. The STEC-positive samples were subjected to further isolation processes of STEC, further PCR and antibiotic susceptibility tests.

\subsection{DNA Extraction and Polymerase Chain Reac- tion Assay}

Prior to detection of the strains by PCR, the DNA was extracted from the bacteria on the culture plates according to the previously described protocol with some modification (18). Briefly, one heterogenic loopful of the grown bacteria from the first area of the MacConkey agar plate was taken and homogenized in $25 \mu \mathrm{L}$ distilled water in a 1.5-mL microtube. The resulting suspension was placed in a boiling water bath at $100^{\circ} \mathrm{C}$ for 10 minutes and centrifuged at $15000 \mathrm{rpm}$ for five minutes in a microcentrifuge (Peqlab, Germany). The supernatant containing bacterial DNA was transferred to a new tube and processed for PCR detection of the stx1, stx2 and eaeA genes.

The information related to the oligonucleotide primers (Faza Biotech, Iran) are shown in Table 1. The PCR was performed in a reaction volume containing $5 \mu \mathrm{L}$ of the extracted DNA, $2.5 \mu \mathrm{L}$ PCR buffer (10x), $0.5 \mu \mathrm{L}$ deoxynucleoside 5-triphosphate, $0.5 \mu \mathrm{L}$ of each primer, $0.25 \mu \mathrm{L}$
Taq DNA polymerase $500 \mathrm{U}(5 \mathrm{U} / \mu \mathrm{L})$, and $1.5 \mu \mathrm{L} \mathrm{MgCl}_{2}(20$ $\mathrm{mM}$ ) (CinnaGen Co., Iran), adjusted to a total volume of $25 \mu \mathrm{L}$ with sterile deionized water. The reaction was carried out by an amplification thermal cycler (Peqlab, Germany). The procedure consisted of initial denaturation at $96^{\circ} \mathrm{C}$ for minutes, followed by 32 cycles of template denaturation at $94^{\circ} \mathrm{C}$ for 20 seconds. The annealing and extension conditions were variable for each gene (Table 2 ). The final cycle was followed by incubation of the reaction mixture at $72^{\circ} \mathrm{C}$ for six minutes.

The PCR products were analyzed by electrophoresis on $1.5 \%$ agarose gel. The results were compared with those of ATCC standard strains of E. coli ATCC 43890 (stx1), E. coli ATCC 43889 (stx2) and E. coli ATCC 43887 (eaeA). E. coli ATCC 11775 was included as a negative control in all the assays.

\subsection{Isolation and Identification of Escherichia coli}

After reculturing the PCR-positive samples, the single lactose positive colonies grown on the fourth area of the MacConkey agar plates, suspected to be E. coli, were subjected to another culture on MacConkey agar plates. The pure cultures were further processed for DNA preparation and screening by PCR; so, they were isolated as the final colonies containing stx1, stx2 and/or eaeA. All the PCR-positive strains were subjected to biochemical tests including triple sugar iron agar (TSI), sulfide indole motility (SIM), citrate agar, and methyl red and VogesProskauer (MRVP) to confirm the identification of E. coli strains. Finally, the possible presence of $0157: H 7$ in the isolated strains was investigated through PCR for the presence of $\mathrm{rbfO} 157$ and fliCh7 genes.

\subsection{Antibiotic Susceptibility Test}

In addition to assessment of genotype diversity, a phenotypic analysis was implemented. For this purpose, the isolated strains were tested against seven groups of antibiotics (HiMedia Laboratories Co., India) including amino-penicillin (ampicillin), carbapenem (imipenem), the first through fourth generations of cephalosporins (cephalothin, ceftazidime, ceftriaxone, and cefepime), tetracycline, aminosides/aminoglycosides (gentamicin, amikacin, kanamycin, streptomycin), phenicol (chloramphenicol), and quinolones (ciprofloxacin, norfloxacin), using the standard disk diffusion method (24). The contents of the antibiotic disks are shown in Table 3.

Table 1. The Sequences of the Oligonucleotide Primers Used in This Study ${ }^{a}$

\begin{tabular}{|c|c|c|c|c|}
\hline Target Gene & Forward Sequence ( 5 ' to $3^{\prime}$ ) & Reverse Sequence (3' to 5') & PCR Product Size, bp & Reference \\
\hline stx1 & GAAGAGTCCGTGGGATTACG & AATAATTATCGACGTAGCGA & 130 & (19) \\
\hline stx2 & ACCGTTTTTCAGATTTTGACACATA & TGACAGACTTTGACGAGGACACAT & 294 & (20) \\
\hline eaeA & GTGGCGAATACTGGCGAGACT & TAAATCCACGCCCAGTCGCAAAAA & 890 & (21) \\
\hline rbf0157 & AAGATTGCGCTGAAGCCTTTG & GACAGGTGCTACGGTTAC & 497 & (22) \\
\hline fliCh7 & GCGCTGTCGAGTTCTATCGAGC & CCTTACCGCTATTTCAGTGGCAAC & 645 & (21) \\
\hline
\end{tabular}

\footnotetext{
a Abbreviation: PCR, polymerase chain reaction.
} 
Mazaheri S et al.

Table 2. Temperatures and Primer Extension Times for the Target Genes

\begin{tabular}{lcc}
\hline Target Gene & Temperature, $^{\circ} \mathbf{C}$ & Extension Time, $\mathbf{s}$ \\
\hline $\boldsymbol{s t x 1}$ & 54 & 10 \\
$\boldsymbol{s t x 2}$ & 59 & 18 \\
eaeA & 54 & 54 \\
flich7 & 68 & 22 \\
rbf0157 & 61 & 30 \\
\hline
\end{tabular}

Table 3. Contents of the Antibiotic Disks Per Microgram ${ }^{a}$

Antibiotic Disk Antibiotic Content 1 ( $\mu$ g Per Each Disk)

\begin{tabular}{ll}
\hline AM & 10 \\
IMP & 10 \\
CF & 30 \\
CAZ & 30 \\
CRO & 30 \\
FEP & 30 \\
TET & 30 \\
GM & 10 \\
AN & 30 \\
K & 30 \\
ST & 10 \\
C & 30 \\
CP & 5 \\
NOR & 10 \\
\hline a Abbreviations: AM, Ampicillin; AN, Amikacin; C, Chloramphenicol; \\
CAZ, Ceftazidime; CF, Cephalothin; CP, Ciprofloxacin; CRO, Ceftriaxone; \\
FEP, Cefepime; GM, Gentamicin; IMP, Imipenem; K, Kanamycin; NOR, \\
Norfloxacin;ST, Streptomycin; TET, Tetracyclin.
\end{tabular}

\section{Results}

\subsection{Polymerase Chain Reaction Assay}

Among the 100 lettuce samples investigated, 8 (8\%) were positive for presence of the stx 1 and $s t x 2$ genes and were defined as STEC. Of the eight STEC strains, three specimens contained stx 1 and five contained stx2, of which, one sample was positive for the presence of both $r b f 0157$ and fliCh7. All the positive samples were isolated from the samples collected from the southern farm lands in the warmer (the second) half of summer. The PCR screening analyses for detection of the eaeA gene were negative for these STEC strains. The agarose gel images of the PCR products for stx1, stx2, rbfO157 and fliCh7 are shown in Figures $1,2,3$ and 4.
Figure 1. Polymerase Chain Reaction Assay for Detection of the stx1 Genes in the Isolated Strains

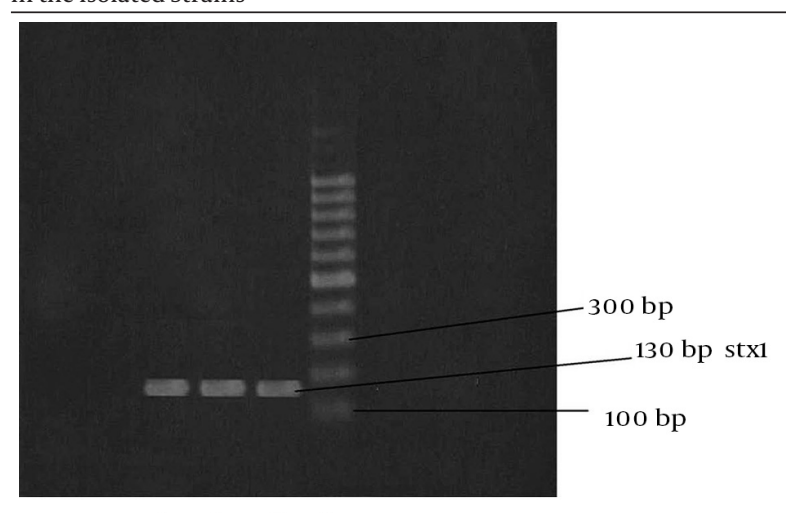

$\begin{array}{llll}1 & 2 & 3 & 4\end{array}$

1, Standard; 2 and 3, positive samples for the stx1 gene (130 bp ); 4, DNA ladder (100 bp).

Figure 2. . Polymerase Chain Reaction Assay for Detection of the stx2 Genes in the Isolated Strains

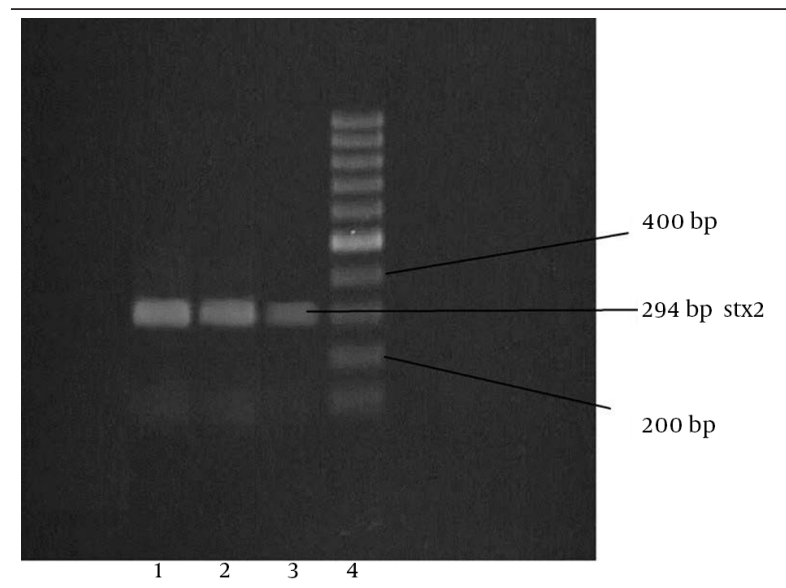

1, standard; 2 and 3, positive samples for the stx2 (294 bp) gene; 4, DNA leader (100 bp).

Figure 3. Polymerase Chain Reaction Assay for Detection of the fliCh7, eaeA and $r b f 0157$ Genes in the Isolated Strains

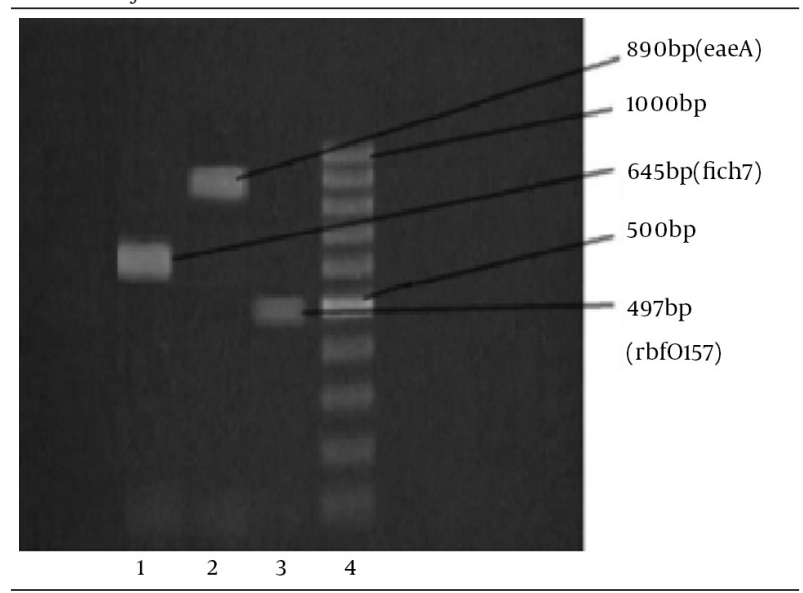

1, positive sample for the fliCh7 gene ( $654 \mathrm{bp}$ ); 2 , positive sample for the rbfO157 gene (497 bp);3, positive sample for the eaeA gene (890 bp); 4, DNA ladder (100 bp). 
Mazaheri S et al.

Figure 4. Polymerase Chain Reaction Assay for the Positive Samples

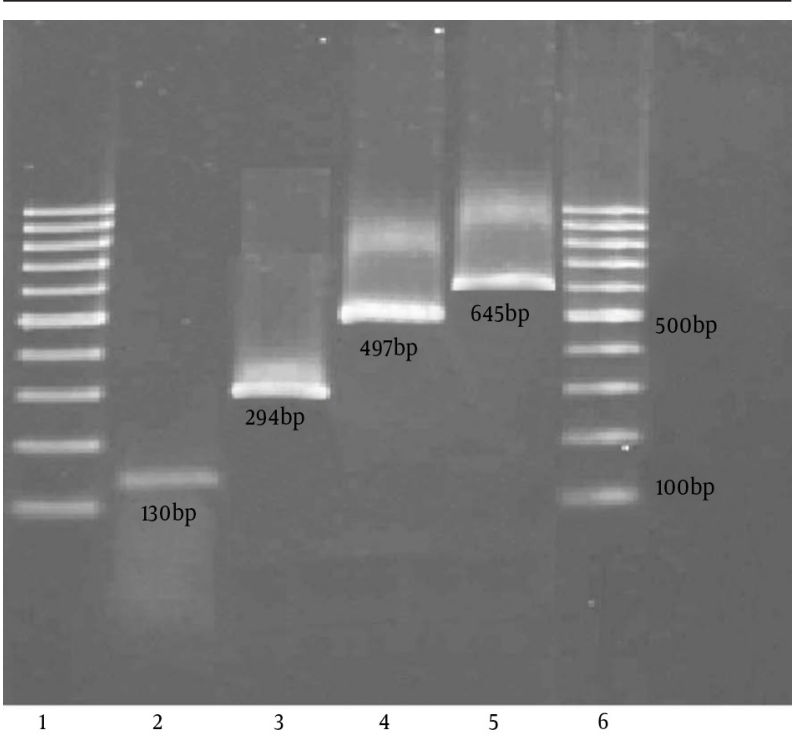

2, stx1 (130 bp); 3, stx2 (294 bp); 4, rbfO157 (497 bp); 5, fliCh7 (645 bp); 1 and 6 , DNA ladder (100 bp)

\subsection{Antibiotic Susceptibility Test}

The two independent susceptibility tests implemented revealed that the isolates were susceptible to all the antibiotics except for tetracycline and ampicillin. Results of the antibiotic susceptibility test are shown in Table 4.

\section{Discussion}

As the highest prevalence of E. coli bacteria can be observed in summer, all the samples were collected during this season. Assessment of the 100 lettuce samples purchased from the farm lands in Tehran indicated that $8 \%$ of the samples were contaminated with STEC strains. This was the first study providing an evidence for contamination of lettuce samples by STEC strains in Tehran, the capital of Iran. The samples were put in E. coli broth medium supplemented with cefixime and then incubated at $37^{\circ} \mathrm{C}$ for 24 hours for proliferation of the pertinent bacteria. This enrichment is critical as the bacteria are stressed under sampling and transformation conditions. Besides, the use of cefixime and the favored environment of the broth allow the growth of particular types of bacteria. Isolation of the strains of interest was made by PCR as a fast, convenient, and highly precise method. Moreover, it was a proper choice because several types of bacteria were present in these samples.

Detection of both stx1 and stx2 genes along with one 0157:H7 strain confirmed the effectiveness of the PCR analysis protocol used in this study. The advantage of this PCR screening method was its remarkable potential for detection of STEC strains in a complex mixture before any purification and obtaining of the isolated colonies. The applied colony screening enabled a reliable assessment of antibiotic resistance and sensitivity because all the impurities and interactions caused by unwanted strains can be excluded by this procedure. Several investigators have assessed the epidemiology of STEC strains in both developed and developing countries (20,21, 23-30). The results obtained in those studies have revealed that overall, consumption of some raw vegetables and food such as hamburger and apple juice could be the plausible sources of STEC strains. In most of the cases, however, the consumption of raw vegetables such as lettuce has been indicated as the principal source of STEC strains $(24,25)$.

We have previously studied the frequency of STEC strains in parsley and leek samples collected from Tehran, where we found that $25 \%$ of the samples contained STEC strains, of which $1 \%$ was 0157:H7 (31). The isolation rate of STEC in the lettuce samples in the present study was lower than that of the parsley and leek. This low isolation rate may be ascribed to the presence of a higher number of other microbial species or E. coli strains in the lettuce samples in addition to STEC strains.

It may also be due to the sampling mode, as higher rates of STEC could be obtained if more than one geographical area was used for sampling. Indeed, the relatively low rates of STEC strains in these samples could be ascribed

\begin{tabular}{|c|c|c|c|c|c|c|c|c|c|c|c|c|c|c|c|}
\hline No. & Antibiotic Strain & TET & $\mathbf{C F}$ & FEP & CAZ & $\mathbf{K}$ & C & AM & ST & IMP & CRO & GM & AN & $\mathbf{C P}$ & NOR \\
\hline 1 & $\mathrm{stx}^{+}$ & $11 \mathrm{R}$ & $24 \mathrm{~S}$ & $16 S$ & $29 S$ & $24 S$ & $27 \mathrm{~S}$ & $6 \mathrm{R}$ & $16 S$ & $18 \mathrm{~S}$ & $27 \mathrm{~S}$ & $18 \mathrm{~S}$ & $20 \mathrm{~S}$ & $23 S$ & $20 \mathrm{~S}$ \\
\hline 2 & $\mathrm{stx}^{+}$ & $12 \mathrm{R}$ & $23 \mathrm{~S}$ & $17 \mathrm{~S}$ & $30 \mathrm{~S}$ & $22 \mathrm{~S}$ & $26 S$ & $7 \mathrm{R}$ & $17 \mathrm{~S}$ & $23 \mathrm{~S}$ & $29 S$ & $20 \mathrm{~S}$ & $21 \mathrm{~S}$ & $25 S$ & $21 \mathrm{~S}$ \\
\hline 3 & $\operatorname{stx} 2^{+}$ & $14 \mathrm{R}$ & $20 \mathrm{~S}$ & $36 \mathrm{~S}$ & $34 \mathrm{~S}$ & $24 \mathrm{~S}$ & $27 \mathrm{~S}$ & $9 \mathrm{R}$ & $16 S$ & $20 \mathrm{~S}$ & $23 \mathrm{~S}$ & $20 S$ & $18 \mathrm{~S}$ & $24 \mathrm{~S}$ & $18 \mathrm{~S}$ \\
\hline 4 & stx $2^{+}$ & $11 \mathrm{R}$ & $18 \mathrm{~S}$ & $34 \mathrm{~S}$ & $30 \mathrm{~S}$ & $22 \mathrm{~S}$ & $25 \mathrm{~S}$ & $6 \mathrm{R}$ & $16 S$ & $21 \mathrm{~S}$ & $24 \mathrm{~S}$ & $17 \mathrm{~S}$ & $20 \mathrm{~S}$ & $24 S$ & $20 S$ \\
\hline 5 & $\operatorname{stx} 2^{+}$ & $12 \mathrm{R}$ & $19 \mathrm{~S}$ & $35 \mathrm{~S}$ & $28 \mathrm{~S}$ & $24 \mathrm{~S}$ & $26 S$ & $8 \mathrm{R}$ & $17 \mathrm{~S}$ & $20 \mathrm{~S}$ & $23 \mathrm{~S}$ & $18 \mathrm{~S}$ & $21 \mathrm{~S}$ & $25 \mathrm{~S}$ & $22 \mathrm{~S}$ \\
\hline 6 & stx $2^{+}$ & $11 \mathrm{R}$ & $20 \mathrm{~S}$ & $32 \mathrm{~S}$ & $32 \mathrm{~S}$ & $20 \mathrm{~S}$ & $24 \mathrm{~S}$ & $8 \mathrm{R}$ & $16 \mathrm{~S}$ & $18 \mathrm{~S}$ & $24 \mathrm{~S}$ & $18 \mathrm{~S}$ & $22 \mathrm{~S}$ & $22 \mathrm{~S}$ & $18 \mathrm{~S}$ \\
\hline 7 & $\operatorname{stx} 2^{+}$ & $13 \mathrm{R}$ & $20 \mathrm{~S}$ & $36 \mathrm{~S}$ & $34 \mathrm{~S}$ & $24 \mathrm{~S}$ & $27 \mathrm{~S}$ & $9 \mathrm{R}$ & $17 \mathrm{~S}$ & $22 \mathrm{~S}$ & $27 \mathrm{~S}$ & $20 \mathrm{~S}$ & $17 \mathrm{~S}$ & $23 \mathrm{~S}$ & $19 S$ \\
\hline 8 & O157:H7 & $12 \mathrm{R}$ & $24 \mathrm{~S}$ & $36 \mathrm{~S}$ & $30 \mathrm{~S}$ & $24 \mathrm{~S}$ & $25 S$ & $7 \mathrm{R}$ & $15 S$ & $21 \mathrm{~S}$ & $26 S$ & $21 S$ & $21 \mathrm{~S}$ & $24 S$ & $20 \mathrm{~S}$ \\
\hline
\end{tabular}


Mazaheri S et al.

to the official health protection policies enforced in this area, regarding the prohibitive legislations and monitoring on the utilization of municipal or industrial waste waters as well as urging the use of chemical fertilizers instead of natural fertilizers. In addition, our positive samples were originated from the farm lands where a wider use of bovine manure was applied for soil nourishment and use of sewages was also applied for watering in some cases. The isolation of one $0157: H 7$ E. coli strain in the present study ( $1 \%$ of all the samples) suggested that this strain survived well in the unfavorable natural conditions of the lettuce samples along with a mixture of other microbial species. Similar studies, conducted in Ireland and Norway, have shown no positive results on detection of 0157:H7 strain in local lettuce samples (15-17).

Using a PCR primer conceived for the eae gene detection (21), no positive result was obtained in this study. The presence of various eae genes among STEC strains encoding the intimin types and subtypes have been demonstrated earlier $(26,27)$. Hence, the negative result of this work upon analysis for this strain while testing only one pair of primers may also be related to the variability of the eae genes among E. coli strains. STEC strains isolated in this investigation were all resistant to tetracycline and ampicillin, a finding in accordance with earlier studies performed in Iran $(28,29)$. For example, Fazeli and Salehi reported that $85.6 \%$ of their isolates showed resistance to tetracycline (28).

Jafari et al. also noted a high rate of resistance to amoxicillin and tetracycline among STEC strains with an observed 5\% multi-resistance to more than six antibiotics (29). In other areas such as Romania and India, resistance to ampicillin and both ampicillin and tetracycline has also been reported $(30,32)$. The presence of multi-resistance among the STEC strains isolated from lettuce may be important from the standpoint of transferring the resistant genes to the human microflora, because multidrug resistance may easily be transferred via the mobile genetic elements of E. coli strains (33). As a conclusion, the results of this investigation indicated the possible role of lettuce samples in transmission of STEC strains. It also suggested the presence and/or increase of antibiotic resistance genes among STEC strains isolated in Iran.

\section{Authors' Contributions}

Somaye Mazaheri was the main researcher and wrote and submitted the manuscript; Siavosh Salmanzadeh-Ahrabi was the supervisor of the thesis; Mohammad Mahdi Aslani was the thesis reader.

\section{References}

1. Kaper JB, Nataro JP, Mobley HL. Pathogenic Escherichia coli. Nat Rev Microbiol. 2004;2(2):123-40.

2. Karmali MA. Infection by Shiga toxin-producing Escherichia coli: an overview. Mol Biotechnol. 2004;26(2):117-22.

3. Bopp CA, Greene KD, Downes FP, Sowers EG, Wells JG, Wachsmuth IK. Unusual verotoxin-producing Escherichia coli associated with hemorrhagic colitis. J Clin Microbiol. 1987;25(8):1486-9.
4. Paton JC, Paton AW. Pathogenesis and diagnosis of Shiga toxin-producing Escherichia coli infections. Clin Microbiol Rev. 1998;11(3):450-79.

5. Tauxe RV. Emerging foodborne diseases: an evolving public health challenge. Emerg Infect Dis. 1997;3(4):425-34.

6. Sivapalasingam S, Friedman CR, Cohen L, Tauxe RV. Fresh produce: a growing cause of outbreaks of foodborne illness in the United States, 1973 through 1997. J Food Prot. 2004;67(10):2342-53.

7. Adwan GM, Adwan KM. Isolation of shiga toxigenic Escherichia coli from raw beef in Palestine. Int J Food Microbiol. 2004;97(1):81-4

8. Ackers ML, Mahon BE, Leahy E, Goode B, Damrow T, Hayes PS, et al. An outbreak of Escherichia coli O157:H7 infections associated with leaf lettuce consumption. J Infect Dis. 1998;177(6):1588-93.

9. Pebody RG, Furtado C, Rojas A, McCarthy N, Nylen G, Ruutu P, et al. An international outbreak of Vero cytotoxin-producing Escherichia coli 0157 infection amongst tourists; a challenge for the European infectious disease surveillance network. Epidemiol Infect. 1999;123(2):217-23.

10. Soderstrom A, Osterberg P, Lindqvist A, Jonsson B, Lindberg A Blide Ulander S, et al. A large Escherichia coli O157 outbreak in Sweden associated with locally produced lettuce. Foodborne Pathog Dis. 2008;5(3):339-49.

11. Uhlich GA, Sinclair JR, Warren NG, Chmielecki WA, Fratamico P. Characterization of Shiga toxin-producing Escherichia coli isolates associated with two multistate food-borne outbreaks that occurred in 2006. Appl Environ Microbiol. 2008;74(4):1268-72.

12. Johnsen G, Wasteson Y, Heir E, Berget OI, Herikstad H. Escherichia coli $0157: \mathrm{H} 7$ in faeces from cattle, sheep and pigs in the south west part of Norway during 1998 and 1999. Int J Food Microbiol. 2001;65(3):193-200.

13. Chapman PA, Siddons CA, Gerdan Malo AT, Harkin MA. A 1-year study of Escherichia coli 0157 in cattle, sheep, pigs and poultry. Epidemiol Infect. 1997;119(2):245-50.

14. Blanco M, Blanco JE, Blanco J, Mora A, Prado C, Alonso MP, et al. Distribution and characterization of faecal verotoxin-producing Escherichia coli (VTEC) isolated from healthy cattle. Vet Microbiol. 1997;54(3-4):309-19.

15. Loncarevic S, Johannessen GS, Rorvik LM. Bacteriological quality of organically grown leaf lettuce in Norway. Lett Appl Microbiol. 2005;41(2):186-9.

16. Avery LM, Killham K, Jones DL. Survival of E. coli O157:H7 in organic wastes destined for land application. J Appl Microbiol. 2005;98(4):814-22.

17. McMahon MA, Wilson IG. The occurrence of enteric pathogens and Aeromonas species in organic vegetables. Int J Food Microbiol. 2001;70(1-2):155-62.

18. Salmanzadeh-Ahrabi S, Habibi E, Jaafari F, Zali MR. Molecular epidemiology of Escherichia coli diarrhoea in children in Tehran. Ann Trop Paediatr. 2005;25(1):35-9.

19. Pollard DR, Johnson WM, Lior H, Tyler SD, Rozee KR. Rapid and specific detection of verotoxin genes in Escherichia coli by the polymerase chain reaction. J Clin Microbiol.1990;28(3):540-5.

20. Svenungsson B, Lagergren A, Ekwall E, Evengard B, Hedlund KO Karnell A, et al. Enteropathogens in adult patients with diarrhea and healthy control subjects: a 1-year prospective study in a Swedish clinic for infectious diseases. Clin Infect Dis. 2000;30(5):770-8.

21. Gannon VP, D'Souza S, Graham T, King RK, Rahn K, Read S. Use of the flagellar $\mathrm{H} 7$ gene as a target in multiplex PCR assays and improved specificity in identification of enterohemorrhagic Escherichia coli strains. J Clin Microbiol. 1997;35(3):656-62.

22. Desmarchelier PM, Bilge SS, Fegan N, Mills L, Vary JC, Jr, Tarr PI. A PCR specific for Escherichia coli O157 based on the rfb locus encoding O157 lipopolysaccharide.J Clin Microbiol.1998;36(6):1801-4

23. Gaydos JM, Harrington BJ. Agar disk diffusion for the quality control testing of Autobac elution disks. Antimicrob Agents Chemother. 1982;21(3):516-8.

24. Qadri F, Svennerholm AM, Faruque AS, Sack RB. Enterotoxigenic Escherichia coli in developing countries: epidemiology, microbiology, clinical features, treatment, and prevention. Clin Microbio Rev. 2005;18(3):465-83.

25. Sodha SV, Lynch M, Wannemuehler K, Leeper M, Malavet M, Schaffzin J, et al. Multistate outbreak of Escherichia coli O157:H7 infections associated with a national fast-food chain, 2006: a 


\section{Mazaheri S et al.}

study incorporating epidemiological and food source traceback results. Epidemiol Infect. 2011;139(2):309-16.

26. Blanco JE, Blanco M, Alonso MP, Mora A, Dahbi G, Coira MA, et al. Serotypes, virulence genes, and intimin types of Shiga toxin (verotoxin)-producing Escherichia coli isolates from human patients: prevalence in Lugo, Spain, from 1992 through 1999. J Clin Microbiol. 2004;42(1):311-9.

27. Kumar HS, Karunasagar I, Teizou T, Shima K, Yamasaki S. Characterisation of Shiga toxin-producing Escherichia coli (STEC) isolated from seafood and beef. FEMS Microbiol Lett. 2004;233(1):173-8.

28. Fazaeli H, Salehi R. Antibiotic resistance pattern in Shiga toxinproducing Escherichia coli isolated from diarrheal patient in $\mathrm{Al}$ zahra hospital Isfahan, Iran. Res Pharm Sci. 2007;2:29-33.

29. Jafari F, Hamidian M, Rezadehbashi M, Doyle M, SalmanzadehAhrabi S, Derakhshan F, et al. Prevalence and antimicrobial resistance of diarrheagenic Escherichia coli and Shigella species as- sociated with acute diarrhea in Tehran, Iran. Can J Infect Dis Med Microbiol. 2009;20(3):e56-62.

30. BodocziFlorea A, Tom . Antimicrobiol Susceptibility of Escherichia coli Isolated from Aries River.Analele Universitat ii din Oradea. Romania: FasciculaBiologie; 2011

31. Salmanzadeh-Ahrabi S, Mohammadpor-ghazi F, Mazaheri S, Mousavi M, Falsafi T. Frequency of shiga toxigenic Esherichia coli in raw vegetable samples collected from Tehran. J App Biol. 2012;51:48-56.

32. Khan A, Das SC, Ramamurthy T, Sikdar A, Khanam J, Yamasaki S, et al. Antibiotic resistance, virulence gene, and molecular profiles of Shiga toxin-producing Escherichia coli isolates from diverse sources in Calcutta, India. J Clin Microbiol. 2002;40(6):2009-15.

33. Falsafi T, Ebrahimi M, Asgarani E, Mirtorabi V. The pattern, association with multidrug-resistance and transferability of plasmidmediated tetracycline resistance inEscherichia coli isolates from the poultry in Iran. Ann Microbiol. 2009;59(2):199-205. 